\title{
Migratory behaviour constrains the phenological response of birds to climate change
}

\author{
Diego Rubolini ${ }^{1, *}{ }^{\text {, Nicola Saino }}{ }^{1}$, Anders P. Møller ${ }^{2,3}$ \\ ${ }^{1}$ Dipartimento di Biologia, Università degli Studi di Milano, via Celoria 26, 20133 Milano, Italy \\ ${ }^{2}$ Laboratoire d'Ecologie, Systématique et Evolution, CNRS UMR 8079, Université Paris-Sud, Bâtiment 360, \\ 91405 Orsay Cedex, France \\ ${ }^{3}$ Center for Advanced Study, Drammensveien 78, 0271 Oslo, Norway
}

\begin{abstract}
Migratory birds may be unable to respond to climate change at their breeding grounds in the same way as residents because they do not experience local environmental conditions until migration has been completed, or because of limited plasticity in response to environmental variation. Indeed, several studies have shown that long-distance migrants have advanced their phenology less than short-distance migrants in recent decades, suggesting a slower phenological response to ongoing climate warming. However, few studies compared the phenological response of species that live year-round within the same climatic region (including residents) with that of species migrating over longer distances. We used an extensive data set on temporal change in spring first singing date (FSD) during 1977-2006 of 56 resident and migratory bird species in Northern Germany to test whether migratory status affected 2 aspects of the phenological response: the temporal trend in FSD and the response of FSD to local temperatures. Species migrating $<4^{\circ}$ latitude (ca. $450 \mathrm{~km}$ ) (less migratory species) showed greater temporal advancement in FSD compared to more migratory species. In addition, the variance in temporal trends was larger among less migratory species. Higher local temperatures were associated with earlier FSD, and multi-brooded species showed a stronger advancement in FSD with higher temperatures than single-brooded species. However, the temperature response was unaffected by migratory status, suggesting that the difference in the temporal trend in FSD between less migratory and more migratory species was mainly due to climatic and/or environmental cues regulating departure of the latter from the wintering areas and/or temporal scheduling of migratory flights, rather than to differential responses of FSD to local temperatures. Therefore, migratory behaviour should be regarded as a life-history trait possibly constraining the phenological response to rapid climatic changes in avian species.
\end{abstract}

KEY WORDS: Brooding $\cdot$ First singing date $\cdot$ Migration distance $\cdot$ Residency

\section{INTRODUCTION}

Living organisms may be unable to effectively track rapidly changing environmental and climatic conditions if such changes occur at a pace that exceeds their capacity to disperse to more favourable areas and their ability to modify behaviour and/or evolve to properly match the novel conditions (Walther et al. 2002, Root et al. 2003, Møller et al. 2004, Gienapp et al. 2008). A case in point is the recent increase in temperature through- out the world, but mainly in temperate and polar regions of the Northern Hemisphere during the last century, with particularly large increases during the last $30 \mathrm{yr}$ (IPCC 2001, 2007). Organisms tend to reproduce at the most favourable time of the year, when food abundance peaks (Lack 1954). With extensive changes in environmental conditions, we should expect the timing of reproduction also to change, as has been demonstrated for numerous bird species, but not for all (Crick \& Sparks 1999, Dunn \& Winkler 1999, Przybylo 
et al. 2000, Sanz et al. 2003, Sheldon et al. 2003, Dunn 2004, Pulido \& Berthold 2004, Visser 2008). A lack of phenological response to changing ecological conditions can generate a mismatch between timing of reproduction and the timing of favourable ecological events, ultimately leading to a decrease in fitness and population declines (Both et al. 2006, Møller et al. 2008).

Climate change may have particularly negative effects on reproduction of migratory birds because they spend the non-breeding part of their annual cycle in areas potentially subjected to different long-term changes in climatic conditions (Berthold 1991), owing to the well-documented spatial and temporal variability in current climatic trends (IPCC 2001, 2007; see also Both \& te Marvelde 2007, Fontaine et al. 2009, Jones \& Cresswell 2010). It has been suggested that earlier onset of spring will allow migratory birds to arrive earlier at their temperate or arctic breeding grounds and hence reproduce earlier (Both et al. 2004, Dunn 2004, Lehikoinen et al. 2004). However, climatic and/or ecological conditions at distant wintering grounds may not have changed or may have changed differently from those conditions at the breeding grounds. This could possibly increase the ecological mismatch of migratory birds at the breeding grounds if they respond to climatic conditions in the wintering grounds as a cue to departure, and/or prevent the birds from preparing for spring migration (the phenology mismatch hypothesis; Jones \& Cresswell 2010). Accordingly, it has been shown that Nearctic (but not Palaearctic) bird species experiencing greater differences between climatic trends in the wintering and breeding grounds have declined more than those experiencing smaller differences (Jones \& Cresswell 2010).

Both arrival and breeding dates of birds have significantly advanced in recent decades (Dunn 2004, Lehikoinen et al. 2004, Rubolini et al. 2007), but advancements were far from homogeneous. In 2 extensive reviews, Lehikoinen et al. (2004) and Rubolini et al. (2007) found that long-distance migrants, spending the boreal winter in tropical areas south of the Sahara, advanced their migration to a smaller extent than short-distance migrants wintering in continental Europe or the Mediterranean. This pattern would be expected if temperature changes in temperate breeding regions and those in tropical wintering areas are not homogeneous, causing long-distance migrants to be exposed to more heterogeneous climatic changes than shortdistance migrants, which to some extent are exposed to temperate climate year round (but see Jonzén et al. 2006). Moreover, results from a previous study of migratory activity of one long-distance migrant (Sylvia borin) and one short-distance migrant (S. atricapilla) during autumn migration suggested that long-distance migrants have a limited plasticity in response to environmental variation compared to short-distance migrants, constraining their ability to adapt to rapidly changing climatic conditions (Pulido \& Widmer 2005). Migratory tendency may thus be considered a constraint on response to climate change if migratory species respond less strongly than residents to climatic variation because of a lack of ability to do so (Both \& Visser 2001, Pulido \& Widmer 2005).

However, most previous studies have failed to investigate how the phenological responses of migratory species differ from those of residents-which would constitute the most obvious natural control group. In fact, temporal trends in arrival date are usually investigated in migrants only (see Lehikoinen et al. 2004), although Jenkins \& Watson (2000) documented a weaker long-term advance in first arrival date among long-distance migrants compared to that of short-distance migrants and to first song date of residents in a Scottish bird community during 1974-1999.

The objectives of the present study were to test to what extent migratory status constrains avian phenological responses, as indexed by both the temporal trend and the response to local temperature variability, in a period of rapidly increasing temperatures in Europe. To this aim, we investigated variation in spring first singing dates (FSD) of 56 bird species at a study site in Northern Germany (Schmidt \& Hüppop 2007) during 1977-2006. The date when song is first heard in late winter and spring is assumed to provide an indication of the onset of the reproductive cycle, with males (and to a lesser extent females) using song as a means of defending breeding territories and attracting mates (Catchpole \& Slater 1995). Start of song activity is generally associated with an increase in testosterone caused by photo-responsiveness induced by increasing day length (Catchpole \& Slater 1995), and modulated by variation in extrinsic conditions, including temperature (e.g. Curio 1959, Garson \& Hunter 1979, Strain \& Mumme 1988). Migratory birds typically start singing at arrival or soon after, with males arriving before females (Catchpole \& Slater 1995). Early arrival and early start of song activity is generally associated with increased mating and reproductive success (e.g. Møller et al. 2003), implying that early start of song activity provides males with a selective advantage.

We predicted that species living in the same climatic region year round should show a stronger temporal trend in FSD (i.e. should advance FSD the most) in a period of spatially variable climate warming compared to species migrating over longer distances. Assuming that phenological responses mainly reflect phenotypically plastic adjustments to environmental variability (Gienapp et al. 2008; see also Przybylo et al. 2000, Gienapp et al. 2007, Balbontín et al. 2009), resident 
species - reproducing early in the season and wintering within the same climatic region of breeding - may be better able to track the variation in both onset and progress of spring than late-breeding migrant species that winter in different climatic regions and do not experience the climatic conditions of the breeding area until arrival.

However, the distinction between resident and migrant species is often far from obvious, and we therefore explored the relationships between the temporal trend in FSD and migratory status using different cut-offs of migration distance to classify individual species as less migratory or more migratory. We also analyzed the effect of migratory status on the response of FSD to local temperature variability, under the general expectation that higher local temperatures should result in earlier FSD. Finally, we explored the seasonal variation in the temporal trend in FSD and in the response of FSD to temperature.

\section{METHODS}

\subsection{Data set}

We used spring FSD data for a community of migratory and resident breeding birds in Parchim (53 $42^{\prime} \mathrm{N}$, $\left.11^{\circ} 50^{\prime} \mathrm{E}\right)$, Northern Germany (Schmidt \& Hüppop 2007). The data were collected by E. Schmidt in a consistent way throughout the study period, thus eliminating any problems of temporal change in effort, or interindividual differences in assessment of FSD (Schmidt \& Hüppop 2007). Observations were made at regular intervals, though not daily during January (Schmidt \& Hüppop 2007). During February-June, a walk that lasted at least $30 \mathrm{~min}$ was the basis for recording the presence and the song of all species. This walk included all major habitats in the study area. Data were combined with observations from regular extensive excursions to major bird areas in the study area (Schmidt \& Hüppop 2007). Thus the records for each year were comparable, and the extent of the observations ensured that all species present in the area had a high chance of being recorded (Schmidt \& Hüppop 2007). The entire year-by-year data set is reported graphically in Schmidt \& Hüppop (2007, their Fig. 4). It should be emphasized that a unique characteristic of this data set is that, differently from previous studies, it differentiates between first observations of a species (first arrival dates) and FSD. Considering only FSD ensures that the phenological data of the different species included in the study are fully comparable. Furthermore, the phenology of the avian community in the study area ensures that no species defending winter territories, which may sing outside the breeding areas, were considered in the original species set reported in Schmidt \& Hüppop (2007). Similarly, no pure winter visitor was considered by Schmidt \& Hüppop (2007). For the purpose of the present study, we considered only data collected during 1977-2006 (total period of Schmidt \& Hüppop's (2007) study was 1963-2006. This was the case because: (1) among the data collected after 1976, there were no major gaps in coverage (Schmidt \& Hüppop 2007); and (2) we aimed to reduce the effects of changes in local population size of species (see Schmidt \& Hüppop 2007), which may affect phenological trend estimates (Lehikoinen et al. 2004). Moreover, this is the period of the study when most temperature warming occurred across Central Europe (IPCC 2001, 2007), and shortening the time series should improve the linearity of the temporal trends, as over the entire period temporal trends of most species were found to be non-linear (Schmidt \& Hüppop 2007).

Criteria for inclusion of a species in the analyses were as follows: (1) the time series of FSD should contain at least 15 years of data; (2) the gap between years with observations should be no greater than $3 \mathrm{yr}$. This data selection was aimed at excluding occasional species and at improving the accuracy of phenological trend estimates. On the whole, out of a total of 60 species included in the original study of Schmidt \& Hüppop (2007), our selection led to the exclusion of 4 species: Jynx torquilla, Dendrocopos medius, Picus viridis and Carduelis cannabina. For the 56 species included in the analyses (see Table S1), the mean $( \pm \mathrm{SD})$ number of years with data was $27.9 \pm 2.4 \mathrm{yr}$ (range $=18$ to 30 yr). FSD was expressed as days since 1 January.

The temporal trend in FSD was estimated for each species as the slope of a linear regression of FSD on year. We then calculated the response of each species' FSD to local temperatures as the slope of a multiple linear regression of FSD on temperature, including also the effect of year as a predictor, in order to quantify the response to temperature while accounting for longterm temporal trends in both local temperatures and FSD. Multicollinearity, as assessed by the variance inflation factor (VIF), did not bias parameter estimates in any of the 56 models. VIF ranged between 1.02 and 1.71 , i.e. well below the commonly accepted thresholds of 5 to 10 , denoting serious collinearity problems (McClave \& Sincich 2003).

As a proxy of local temperatures, we used the mean temperature anomalies of the previous month and the month where the average phenological event occurred across all years. Temperature data were obtained from a NOAA website (www.ncdc.noaa.gov) for a $2.5^{\circ} \times 2.5^{\circ}$ (latitude $\times$ longitude) square area including the study site $\left(52.5^{\circ}\right.$ to $55.0^{\circ} \mathrm{N}, 10.0^{\circ}$ to $\left.12.5^{\circ} \mathrm{E}\right)$. In the period 1977-2006, temperature anomalies during all months considered in the analyses (December to June) showed 
a tendency to increase, albeit only significantly ( $\mathrm{p}<$ 0.05) in February and April (data not shown). The mean temperature increase across all months was $0.061^{\circ} \mathrm{C} \mathrm{yr}^{-1}$ (range 0.016 to $0.117^{\circ} \mathrm{C} \mathrm{yr}^{-1}$ ).

\subsection{Predictors of phenological responses}

\subsubsection{Migratory status}

The main aim of the present study was to compare the phenological responses during a period of temperature warming in resident and migratory birds. However, although the extremes of migratory behaviour may be obvious, these 2 categories of species are often difficult to distinguish for intermediate cases (Cramp 1998). Thus a biologically justified a priori distinction between these 2 categories would be highly arbitrary and unfeasible (see also Visser et al. 2009). Moreover, the spatial correlation of climatic conditions is generally high over short distances (e.g. Hurrell 1995, Werner \& Schönwiese 2002), implying that species that on average move over short distances are expected to respond to climate variation in a similar way as true residents. Finally, birds show a great among-population variability in movement patterns, implying that an unknown fraction of species considered as true residents could make small- to medium-scale migratory movements (e.g. Parus ater; Cramp1998).

To avoid the possible pitfalls associated with an a priori categorization of migratory status, we considered in the analyses many possible cut-offs in migration distance in order to classify species as less migratory or more migratory according to increasing values of migration distances (see Section 2.3). Thus we examined how the phenological response covaried with migratory status, while accounting for other variables potentially affecting the phenological response, in a multiple regression setting (see Section 2.3). Migratory status was coded as a 2-level predictor (less migratory $=0$, more migratory $=1$ ). Exploratory analyses showed that the relationship between the phenological trend and migration distance $\left(\log _{10}[\mathrm{x}+1]\right.$-transformed) was non-monotonic (Fig. S1, Supplement 1, see www.int-res.com/ articles/suppl/c042p045_supp.pdf), thus making any inference based on continuous migration distance difficult to interpret biologically. Indeed, a generalized additive model (GAM) of temporal trend in FSD on migration distance provided a significantly better fit $\left(\mathrm{r}^{2}=\right.$ $0.19)$ than a linear $\left(r^{2}=0.09\right)$, a quadratic $\left(r^{2}=0.07\right)$ or a cubic $\left(\mathrm{r}^{2}=0.08\right)$ fit (GAM versus linear fit, deviance test, $F_{3.26,50.73}=2.99, \mathrm{p}=0.036$; GAM versus quadratic and cubic fit, both $\mathrm{p}<0.015$ ) (GAM was fitted with spline smoothers by means of the mgcv 1.5-5 library of software R, v. 2.8.1; R Development Core Team 2008).
To obtain an estimate of migration distance of each species, we determined the global northernmost and southernmost latitude of the breeding and wintering distributions, respectively, to the nearest tenth of a degree, based on information on breeding and wintering ranges shown on maps in Cramp (1998). Migration distance was simply calculated as the mean of the 2 latitudes during breeding minus the mean of the 2 latitudes during winter. We assigned a migration distance equal to 0 to species considered as residents in the study area by Schmidt \& Hüppop (2007).

\subsubsection{Population trend and size}

It has been repeatedly shown that the changes in timing of first phenological events depends on the population size of the species, because: (1) early individuals are more likely to occur when the population size is large; and (2) genetic variance (and thus the chances of the occurrence of early outlier individuals) increases with population size (review in Lehikoinen et al. 2004; see also Tryjanowski et al. 2005). Across species, it is therefore possible that change in phenology at least partly reflects concomitant changes in detectability or phenotypic variance following population fluctuations. Therefore, we included in the analyses an estimate of the population trends of each species at the European continental level (west of the Ural Mountains) as well as at a national level (Germany), as reported in BirdLife International (2004). Europe-wide breeding population trends were derived from BirdLife International (2004) (where separate trends for the periods 1970-1990 and 1990-2000 are reported) and were expressed on a 7 point scale-large decline (-3), moderate decline $(-2)$, small decline $(-1)$, stable $(0)$, small increase $(+1)$, moderate increase $(+2)$ to large increase (+3) (see Møller et al. 2008). Trends in the 2 periods were positively correlated $(\mathrm{r}=0.27, \mathrm{p}=0.048, \mathrm{n}=56$ species; see also Sanderson et al. 2006, Møller et al. 2008), and were averaged to obtain a single estimate of population change for 1970-2000. Trends for Germany were available for 1990-2000 only, and were reported on a 11 point scale, reflecting different percentages of change (from -5 , reflecting a large decrease, to +5 , reflecting a large increase; see BirdLife International 2004 and Sanderson et al. 2006 for details of codings). The trends for Germany during 1990-2000 were positively correlated with the average European trends during 1970-1990 and 1990-2000 ( $\mathrm{r}=0.54$, $\mathrm{p}<0.001$, $\mathrm{n}=56$ ). As a rough estimate of the population size of each species, we included European population sizes (west of the Ural Mountains; average between minimum and maximum values) or German population sizes, as reported in BirdLife International (2004). All 
analyses were run by including alternatively either European trends and associated European population sizes, or German trends and associated population sizes. This was done because European trends encompass the entire period of study, whereas the German trends, that likely reflect local population trends more reliably, were available only for the last decade of the study, and might perhaps be less representative of the trends for the entire period. For simplicity, we present the results of the analyses that include European data, check for consistency with results obtained when considering German data, and discuss meaningful differences in the outcome of analyses.

\subsubsection{Body mass, moult strategy, nest site and number of broods}

Body mass was included as a possible predictor in the analyses because we speculated that, thanks to their smaller surface to volume ratio, FSD of larger species might be less susceptible to temperature variability than that of smaller species. We obtained body masses from Cramp (1998) or, if data were unavailable, from Dunning (1993). Moult strategy, nest site and number of broods were included as possible predictors in the analyses because previous studies demonstrated that these variables were associated with variation in timing of migration or phenological trend across species (Rubolini et al. 2005, Møller et al. 2008, Végvári et al. 2010). Specifically, earlier studies showed that birds moulting in winter arrive later (Rubolini et al. 2005) and advance arrival date the least (Végvári et al. 2010), while multi-brooded species (i.e. species raising more than a single brood per year) tend to advance arrival date the most (Møller et al. 2008, Végvári et al. 2010). Moreover, multibrooded species have expanded the duration of their breeding season more than single-brooded species (Møller et al. 2010). Finally, cavity nesting species arrive earlier because of intense competition for limiting nest sites (Rubolini et al. 2005), and selection for early breeding may lead cavity nesting species to advance migration more than species building their own nest. Moult strategy and nest site were coded according to Rubolini et al. (2005) — moult strategy: $0=$ wing feather moult not taking place in winter, $1=$ wing feather moult occurring in winter; nest site: $0=$ species building their own nest, $1=$ species using preexisting cavities. The number of broods refers to the maximum number of broods per season recorded in a species (see also Møller et al. 2008), as derived from Cramp (1998). The entire data set is enclosed as an electronic supplement (Table S1), see www.int-res. com/articles/suppl/c042p045_supp.pdf.

\subsection{Statistical and comparative analyses}

The relationship between the temporal trend in FSD and migratory status was investigated by multiple regression analyses including as additional predictors the European population trend, population size $\left(\log _{10^{-}}\right.$ transformed), body mass ( $\log _{10}$-transformed), moult strategy, nest site and number of broods. All models were also run by including population trends and population size at the national scale (see Section 2.2.2 and 'Results').

We ran 12 models, each with a different coding of less migratory species according to increasing cut-offs of migration distance. In the first model, less migratory species were those with a migration distance equal to 0 (i.e. species migrating $<1^{\circ}$ latitude), whereas all the other species were coded as more migratory. In the subsequent models, we coded as less migratory those species migrating over progressively increasing distances, with an increase of at least $1^{\circ}$ latitude at each step (i.e. we coded as less migratory species migrating $<2^{\circ},<3^{\circ}$, $<4^{\circ}$ latitude, and so on, and as more migratory the remaining species), until reaching the minimum migration distance of long-distance migrants (i.e. species mainly wintering in Africa) included in the study (20.74 ${ }^{\circ}$ latitude, migration distance of Streptopelia turtur). This implies that the last categorization of migratory behaviour (less migratory species are those migrating $<20^{\circ}$ latitude, more migratory species are those migrating at least $20^{\circ}$ latitude) is, de facto, a comparison between short-distance and long-distance migrants as commonly classified in studies of bird migration (e.g. Lehikoinen et al. 2004, Rubolini et al. 2007). All the models were replicated by using the response of FSD to local temperatures as the dependent variable. The fit of models was compared by means of Akaike's information criterion (AIC) values. According to Burnham \& Anderson (2002), as a general benchmark we considered models with a factor causing a decrease in AIC $>2.00$ to provide a better fit than other models.

In comparative analyses, species-specific data are not statistically independent due to similarity in phenotype among species caused by common descent. We controlled for such statistical dependence by calculating independent linear contrasts for each variable according to the method developed by Felsenstein (1985). All the regression analyses described above were thus replicated using contrast values instead of species-specific data. We used a composite phylogeny based on Sibley \& Ahlquist (1990), combined with those in Blondel et al. (1996), Badyaev (1997), Leisler et al. (1997), Johnson et al. (2001), Barker et al. (2004), Drovetski et al. (2004) and Gill et al. (2005) (Fig. S2). We adopted the CAIC library of $\mathrm{R}$ (http://r-forge.rproject.org/projects/caic/) for calculating contrasts (ac- 
cording to the method proposed by Purvis \& Rambaut 1995). All branches were assigned the same length. Contrasts were analyzed by forcing regressions through the origin because the dependent variable is not supposed to have changed when the independent variable has not changed (Purvis \& Rambaut 1995).

Statistical analyses were made in R (v. 2.8.1; R Development Core Team 2008). Means and parameter estimates are presented $\pm \mathrm{SE}$, unless otherwise stated.

\section{RESULTS}

\subsection{Seasonality and temporal trend in FSD}

Mean FSD ranged between 22 January (Eurasian nuthatch Sitta europaea) and 19 May (red-breasted flycatcher Ficedula parva). On the whole, species tended to advance FSD during 1977-2006: the mean slope of the relationship between FSD and year was $-0.32 \pm$ $0.06 \mathrm{~d} \mathrm{yr}^{-1}$ (1-sample $t$-test, $\left.t_{55}=-5.52, \mathrm{p}<0.001\right)$. In fact, among the 56 species considered, only 8 species showed a trend towards delaying FSD. The amongyear variance $\left(\log _{10}\right.$-transformed) in FSD was negatively related to mean FSD across species ( $\mathrm{r}=-0.85, \mathrm{n}=$ 56, p < 0.001) (see also Schmidt \& Hüppop 2007), implying that species that started singing earlier showed a greater among-year variability in onset of singing. Moreover, the temporal advancement in FSD tended to weaken in species starting to sing in late spring (mean slope $=0.0034 \pm 0.0016, t_{54}=2.16, \mathrm{p}=0.036, \mathrm{r}^{2}=0.08$; Fig. 1a). A quadratic model provided a slightly better fit $\left(r^{2}=0.14\right)$, although the quadratic term of date was marginally non-significant $\left(t_{53}=-1.90, \mathrm{p}=0.062\right.$; Fig. 1a).

\subsection{Seasonality and response of FSD to local temperatures}

The response of FSD to the average temperature in the 2 preceding months was quantified as the slope associated with temperature derived from a multiple regression model of FSD including both year and temperature as predictors (see 'Methods'). There was a marked tendency towards earlier FSD with increasing temperatures (mean slope: $-1.10 \pm 0.23 \mathrm{~d}^{\circ} \mathrm{C}^{-1}$; 1 -sample $t$-test, $\left.t_{55}=-4.71, \mathrm{p}<0.001\right)$. The response to temperature weakened in species starting to sing later (mean slope $=0.015 \pm 0.006, t_{54}=2.27, \mathrm{p}=0.027, \mathrm{r}^{2}=$ 0.09). A quadratic model provided a significantly better fit $\left(\mathrm{r}^{2}=0.22\right.$; statistics for the squared term: $t_{53}=2.96$, $p=0.005$; Fig. 1b), showing that the response to temperature varied non-monotonically according to the progression of the season, being strongest among species starting to sing in March.
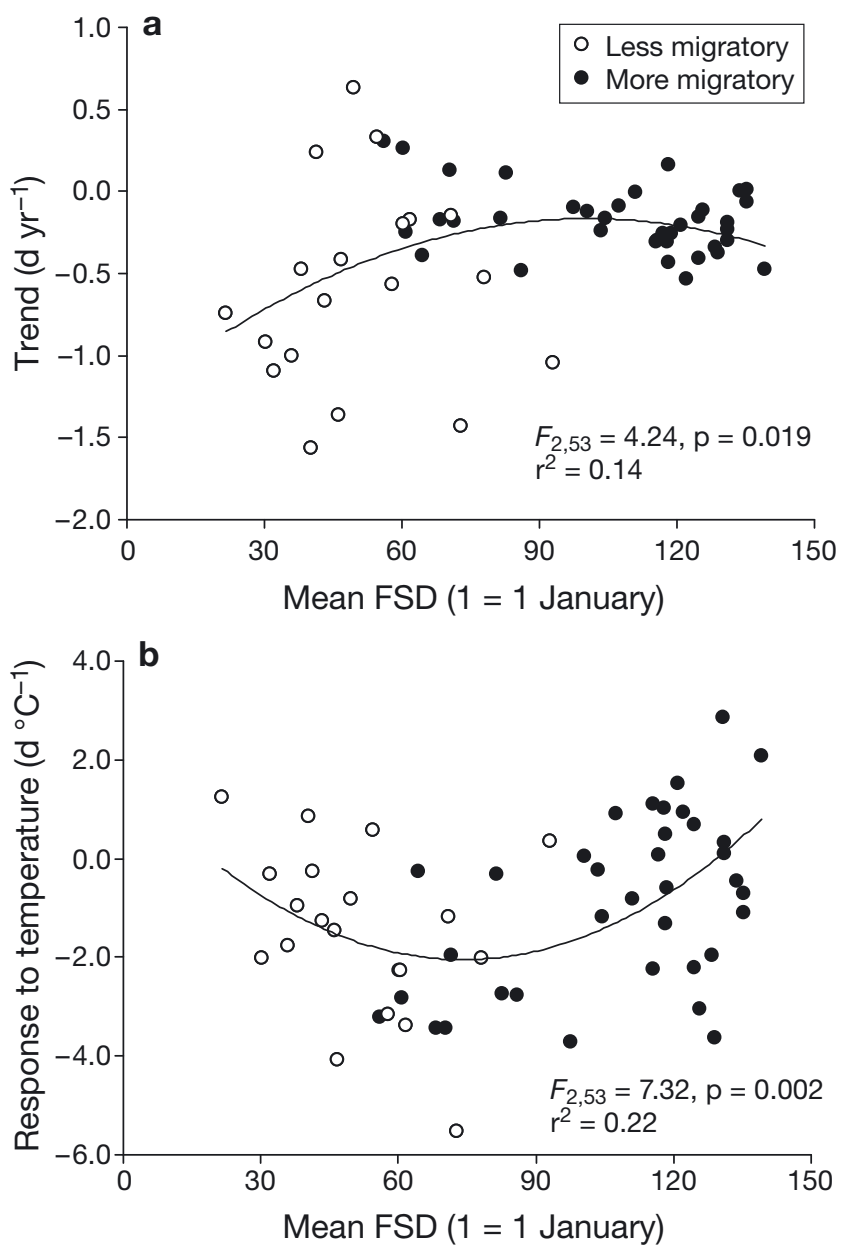

Fig. 1. Relationship between (a) temporal trend in first singing date (FSD) or (b) response of FSD to local temperatures (see 'Methods') and mean species-specific FSD during 1977-2006 ( $\mathrm{n}=56$ species). Less migratory species: migrating $<4^{\circ}$ latitude; more migratory species: those not defined as 'less migratory'

\subsection{Migratory status and temporal trend in FSD}

The model with the lowest AIC was the one with migratory status contrasting species migrating $<4^{\circ}$ latitude (corresponding to ca. $450 \mathrm{~km}$ ) with those migrating $>4^{\circ}$ latitude (Fig. 2). The differences in AIC compared to the nearest best ranking models were 1.65 (less migratory species: species migrating $<3^{\circ}$ latitude) and 1.90 (less migratory species: species migrating $<5^{\circ}$ latitude), respectively (Fig. 2). Parameter estimates for the best fitting model are shown in Table 1. Migration status was the only variable significantly predicting change in FSD, with less migratory species showing the strongest response compared to more migratory species. The effects of all the other predictors were weak and non-significant (Table 1). The 


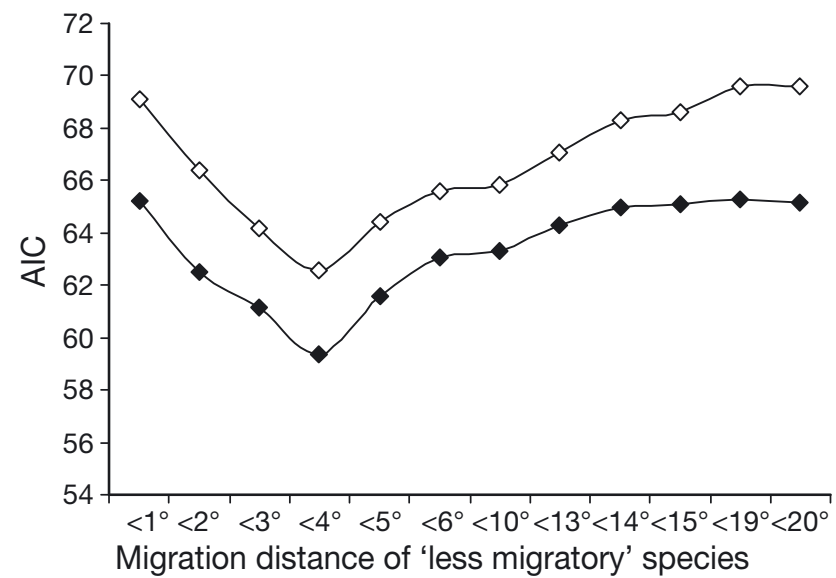

Fig. 2. Akaike's information criterion (AIC) values of multiple regression models of temporal trend in first singing date in relation to migratory status (less migratory or more migratory) and several other predictors (see 'Methods' for details). In each model, a different coding of less migratory species was adopted, according to increasing cut-off values of migration distances (expressed in degrees latitude). The model with the lowest AIC value was the one with a $4^{\circ}$ latitude migration distance cut-off. See Table 1 for statistics. Open diamonds: results of modelling while including as predictors Europe-wide population trends and associated population sizes; filled diamonds: results of modelling while including as predictors German trends and associated population sizes (see 'Section 2.2.2' for details) mean species-specific slopes of FSD on year were $-0.59 \pm 0.14 \mathrm{~d} \mathrm{yr}^{-1}$ for less migratory species $(\mathrm{n}=19)$


( $\mathrm{n}=37$ ), respectively.

The variance in slopes differed according to migration status, with greater heterogeneity in slopes among less migratory versus more migratory species (Levene's test, $F_{1,54}=25.14, \mathrm{p}<0.001$ ). This may affect the reliability of SE of estimates of the multiple regression model shown in Table 1 (Zuur et al. 2009); therefore, we ran the same model accounting for heteroscedasticity by using generalized least squares regression, allowing the 2 levels of the covariate migratory status to have a different variance (using the gls function of the nlme library of R 2.8.1; see Zuur et al. 2009 for details). The results were qualitatively unchanged (effect of migratory status, $t_{48}=2.37, \mathrm{p}=0.022$ ).

Interestingly, there was no difference in the longterm phenological response between short-distance (including residents) and long-distance migrants (see Section 2.3), as shown by the effect of migratory status in the model where less migratory species were defined as species migrating $<20^{\circ}$ latitude $\left(t_{48}=0.47\right.$, $\mathrm{p}=0.64)$. This model had a difference in AIC compared to the best model equal to 7.04. Results were also unchanged if species with an estimated migration distance of 0 were excluded (effect of migratory status, $\left.t_{37}=0.05, \mathrm{p}=0.96\right)$.

The results of the AIC-based modelling

Table 1. Parameter estimates $( \pm \mathrm{SE})$ for the best-fitting multiple regression model of the long-term temporal trend in first singing date (FSD), where less migratory species were defined as those migrating $<4^{\circ}$ latitude (see Sections 2.3 and 3.3$)$; and parameter estimates $( \pm \mathrm{SE})$ for the multiple regression model of the response of FSD to local temperatures. For ease of comparison, in the second model less migratory species were also defined as those migrating $<4^{\circ}$ latitude. Sample size is 56 species; $\mathrm{p}$-values for phylogenetically independent linear contrasts ( $\mathrm{p}_{\text {cont } i} \mathrm{n}=55$ contrasts in both models) are also shown. The models based on contrasts were forced through the origin (Purvis \& Rambaut 1995)

\begin{tabular}{|lrrrl|}
\hline Predictors & Estimate & $t$ & $\mathrm{p}$ & $\mathrm{p}_{\text {cont }}$ \\
\hline Temporal trend in FSD (1977-2006) & & & & \\
Migratory status & $0.359 \pm 0.139$ & 2.58 & 0.013 & 0.036 \\
Population trend & $0.050 \pm 0.069$ & -0.71 & 0.48 & 0.53 \\
Population size & $0.062 \pm 0.102$ & 0.61 & 0.54 & 0.18 \\
Body mass (log) & $-0.187 \pm 0.134$ & -1.40 & 0.17 & 0.68 \\
Moult strategy & $-0.130 \pm 0.147$ & -0.89 & 0.38 & 0.90 \\
Nest site & $-0.130 \pm 0.142$ & -0.91 & 0.37 & 0.44 \\
Number of broods & $-0.027 \pm 0.077$ & -0.35 & 0.73 & 0.48 \\
Response of FSD to local temperatures & & & \\
Migratory status & $0.741 \pm 0.549$ & 1.34 & 0.18 & 0.88 \\
Population trend & $-0.039 \pm 0.276$ & -0.14 & 0.89 & 0.27 \\
Population size & $-0.264 \pm 0.402$ & -0.66 & 0.51 & 0.96 \\
Body mass (log) & $-0.676 \pm 0.529$ & -1.28 & 0.21 & 0.23 \\
Moult strategy & $-0.128 \pm 0.579$ & -0.22 & 0.83 & 0.84 \\
Nest site & $0.727 \pm 0.563$ & 1.29 & 0.20 & 0.83 \\
Number of broods & $-0.868 \pm 0.304$ & -2.85 & 0.006 & 0.032 \\
\hline
\end{tabular}
procedure were qualitatively unchanged when the analyses were based on contrasts (details not shown for brevity). p-values for the best ranking model for contrast analyses (migration distance of less migratory species $<4^{\circ}$ latitude) are shown in Table 1 . The results were qualitatively similar to the analyses based on species-specific data, with only migratory status significantly predicting the long-term phenological response (Table 1).

Results were also qualitatively unaltered when we included German trends and associated population sizes as predictors (Fig. 1). Parameter estimates for the best fitting model confirmed a statistically significant effect of migratory status (estimate $\left.=0.323 \pm 0.139, t_{48}=2.33, \mathrm{p}=0.024\right)$, and revealed a marginally non-significant effect of German population trends (estimate = $\left.-0.097 \pm 0.050, t_{48}=-1.92, \mathrm{p}=0.061\right)$. Results were similar if the analyses were based on contrasts: in this case, the effects of both migratory status and population trends on change in FSD were marginally non-significant ( $p=0.067$ in both cases) in 
the model including all predictors. However, both became statistically significant if the other nonsignificant predictors (all p > 0.59) were removed (migratory status, estimate $=0.360 \pm 0.161, t_{53}=2.24$, $\mathrm{p}=0.029$; German population trend, estimate $=-0.094$ $\left.\pm 0.047, t_{53}=-2.00, \mathrm{p}=0.050\right)$.

\subsection{Migratory status and response of FSD to local temperatures}

The same approach that was adopted to examine among-species temporal variation in the phenological response was used to investigate the response of FSD to temperatures. A plot of AIC values revealed a general similarity in model fit, with a maximum difference in AIC between the best fitting and worst fitting model equal to 2.45 (data not shown). Thus there was little evidence that our different codings of migratory status, independently of how species were classified, affected the response of FSD to temperatures. For comparison with previous analyses, parameter estimates for the model where less migratory species were those migrating $<4^{\circ}$ latitude are shown in Table 1. The only variable significantly affecting the response of FSD to temperatures was the number of broods, with species raising more broods showing the greatest sensitivity in the onset of singing to local temperatures, irrespective of migration status (Table 1, Fig. 3). The effect of migratory status was not significant in any of the models ( $t$-values always $<11.35 \mid, p>0.18$ ), whereas the effect of number of broods was negative and statistically significant in all models ( $t$-values always $<-2.39, \mathrm{p}<0.02$ ). The absence of any effect of migratory status on the response to temperature was further confirmed by the inspection of AIC values for a model also including the interaction term between the different categorizations of migratory status and number of broods (the interaction term was tested because the number of clutches in less migratory and more migratory species may differ, see Böhning-Gaese et al. 2000; difference in AIC between best and worst fitting model $=2.59 ; t$-values for the interaction term always $<|0.69|, p>0.49)$. Finally, there was no significant difference in the among-species variance in the response to temperature according to the different categorizations of migratory status (Levene's test, $\mathrm{n}=$ 12 tests, all $F_{1,54}<2.30, \mathrm{p}>0.13$ ).

The results of the modelling procedure were qualitatively unchanged when the analyses were based on contrasts (see also Table 1), and when German trends and associated population sizes were included as predictors, both in species-specific and in contrast-based analyses (data not shown).

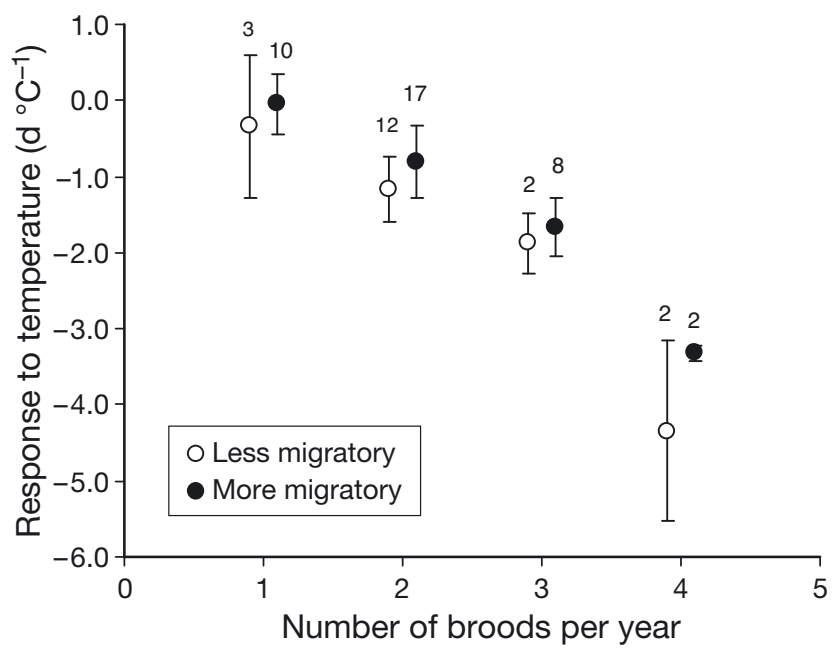

Fig. 3. Relationship between response of first singing date to local temperatures and maximum number of broods laid per year in less migratory (migrating $<4^{\circ}$ lat.) and more migratory species. Data are mean \pm SE. Numbers above bars: sample sizes

\section{DISCUSSION}

The main findings of the present study were that migratory status affected the species-specific longterm temporal trend in FSD, with less migratory species (migrating $<450 \mathrm{~km}$ ) showing the strongest advancement compared to other species, but not the response of FSD to local temperatures. Less migratory species also showed a significantly more heterogeneous temporal trend compared to more migratory species. Finally, the maximum number of broods laid per season predicted the response of FSD to local temperatures independently of migratory status, with local temperatures affecting FSD more strongly in multi-brooded species than in single-brooded ones. The results were not confounded by changing population size of species in the study period.

The smaller temporal advancement in FSD among species migrating more than $450 \mathrm{~km}$ was not simply due to differences in seasonal timing of FSD between less and more migratory species (see e.g. Fig. 1a and Lehikoinen et al. 2004). In fact, the effect of migratory status on temporal trend in FSD remained statistically significant $\left(t_{52}=2.58, \mathrm{p}=0.013\right)$ in a multiple regression model including mean species-specific FSD and its squared term, both instead becoming nonsignificant $(\mathrm{p}>0.2$; results were unchanged if the squared term of mean FSD was removed, data not shown). Thus more migratory species, which frequent disparate climatic regions during the course of their annual cycle, seem unable to take advantage of milder temperatures to extend their breeding season and/or to match the advancement of the phenology of spring 
events in the same way as less migratory species wintering in the same climatic region of breeding. Interestingly, we did not document a difference between the so-called short-distance (species that mainly do not winter south of the Sahara) and long-distance migrants (species that mainly winter south of the Sahara) that has been observed in most previous studies analysing phenological trends in relation to migratory status (Lehikoinen et al. 2004, Rubolini et al. 2007). However, this is the first study to explicitly analyse singing dates only, rather than first arrival (or mean migration) dates, so the results are not directly comparable (see also Jenkins \& Watson 2000 for a study where FSD of residents and first arrival dates of migrants were compared). Indeed, it is possible that the difference between temporal trends in first arrival dates and trends in FSD vary according to migration distance if the interval between arrival and singing has become shorter in long-distance migrants (e.g. Both \& Visser 2001) compared to short-distance migrants. Unfortunately, insufficient data exist on species-specific first arrival date and FSD in the current data set to test this hypothesis (Schmidt \& Hüppop 2007).

From a methodological standpoint, it is interesting to note that the greatest difference in temporal trends in FSD between less migratory and more migratory species was observed when species migrating $<450 \mathrm{~km}$ were classified as less migratory. This suggests that the spatial covariation between climatic drivers of phenological change in birds is high up to a migration distance of this magnitude, and decreases with further increasing geographical distances. On the other hand, at progressively smaller migration distances, and particularly among locally resident species, variance in phenological trends increases considerably (see Fig. S1), resulting in less reliable estimates of the effect of migratory status on temporal trends in FSD.

In addition, less migratory species showed considerably more variation in rate of FSD advancement than more migratory species. Two non-mutually exclusive explanations may account for such a difference. Firstly, environmental variance is smaller later in spring, and onset of singing in less migratory species may be highly sensitive to minor local temperature variation (i.e. birds may start singing under even short warm spells), thus inflating the variance of estimates of longterm temporal trends. Secondly, intense natural and sexual selection associated with migration (e.g. Spottiswoode \& Møller 2004, Møller 2007) may account for the reduced variance in temporal trends in FSD among more migratory species. Both explanations are compatible with the far greater among-year variance in FSD in less migratory as compared to more migratory species (345.8 versus 68.4, Mann-Whitney $U$-test, p < 0.001), and with the strong decrease in among-year variance in FSD in the course of the season. Alternatively, the larger variance in both FSD and phenological responses among less migratory versus more migratory species may be caused by the shorter sampling period of the latter, because more migratory species are absent from the study area in the early part of the breeding season, thus reducing the variability in FSD recording.

The response of FSD to variation in local temperatures indicated that most species tended to start singing earlier in warmer years, consistent with the expectation. However, the response to temperature of less migratory and more migratory species was of similar magnitude, implying that a similar change in temperatures triggered onset of singing irrespective of migratory status. Thus differences in temporal trends in FSD between less migratory and more migratory species do not depend on differential temperature responses, implying that reduced plasticity in response to environmental variability (see Pulido \& Widmer 2005) is unlikely to cause smaller advancements in migration date in less migratory versus more migratory species. This result may depend on the fact that local temperatures can affect onset of singing only once migratory birds have already reached the study site. This finding thus corroborates the idea that differences in long-term temporal trends in phenology between less migratory and more migratory species (and between short- and long-distance migrants observed in other studies) are related to climatic and/or environmental cues regulating departure of migrants from the wintering grounds and temporal scheduling of migratory steps en route (e.g. Saino et al. 2004, 2007, Tøttrup et al. 2008, Balbontín et al. 2009). Moreover, the response of FSD to temperature was predicted by the maximum number of broods raised per season, with species that lay more broods per year showing stronger temperature responses than single-brooded species. The stronger temperature sensitivity of multibrooded species, irrespective of migratory status, may follow the greater fitness payoffs of an early start of reproduction in these species as compared to singlebrooded ones. Indeed, the selection pressure towards an earlier start of breeding activities may be stronger in multi-brooded species, because it may allow early breeding pairs to lay more than one brood. This finding is also consistent with previous studies documenting stronger advancements in arrival or migration dates in multi-brooded versus single-brooded migratory species (Møller et al. 2008, Végvári et al. 2010). It is also consistent with an increasing duration of the breeding season in response to climate change with the number of broods (Møller et al. 2010).

Finally, we observed a weak negative relationship between population trends in Germany and temporal 
trends in FSD. However, the interpretation of this finding is problematic, since population trends might be a cause or a consequence of the trend in FSD. Indeed, changing population trends may bias trends in FSD if the probability of occurrence and/or detection of an early bird reflects actual population size (Lehikoinen et al. 2004). On the other hand, population trends may be a consequence of interspecific variation in ability to respond to climate change, as assessed by long-term phenological trends (Møller et al. 2008).

In conclusion, we have shown considerable variation in the rate of advancement of FSD during recent decades in birds, with less migratory species showing considerably greater variation than more migratory ones. Such variability may suggest that factors other than migratory status constitute important constraints on phenological responses to climate change. We also found evidence of smaller advancement in FSD in more migratory species compared to less migratory ones, suggesting that migration may indeed constitute an important constraint on the response to spatially and temporally variable climate change.

Acknowledgements. We thank K. and O. Hüppop for useful criticism, and E. Schmidt for his dedicated fieldwork in the past decades. We also thank the associate editor, T. Sparks, and 4 anonymous reviewers for constructive comments.

\section{LITERATURE CITED}

Badyaev AV (1997) Altitudinal variation in sexual dimorphism: a new pattern and alternative hypotheses. Behav Ecol 8:675-690

Balbontín J, Møller AP, Hermosell IG, Marzal A, and others (2009) Individual responses in spring arrival date to ecological conditions during winter and migration in a migratory bird. J Anim Ecol 78:981-989

Barker FK, Cibois A, Schikler P, Feinstein J, Cracraft J (2004) Phylogeny and diversification of the largest avian radiation. Proc Natl Acad Sci USA 101:11040-11045

Berthold P (1991) Patterns of avian migration in light of current global 'greenhouse' effects: a central European perspective. Acta XX Congr Int Ornithol 20:780-786

BirdLife International (2004) Birds in Europe: population estimates, trends and conservation status. BirdLife International, Cambridge

Blondel J, Catzeflis F, Perret P (1996) Molecular phylogeny and the historical biogeography of the warblers of the genus Sylvia (Aves). J Evol Biol 9:871-891

Böhning-Gaese K, Halbe B, Lemoine N, Oberrath R (2000) Factors influencing the clutch size, number of broods and annual fecundity of North American and European land birds. Evol Ecol Res 2:823-839

Both C, te Marvelde L (2007) Climate change and timing of avian breeding and migration throughout Europe. Clim Res 35:93-105

Both C, Visser ME (2001) Adjustment of climate change is constrained by arrival date in a long-distance migrant bird. Nature 411:296-298

Both C, Artemyev AV, Blaauw B, Cowie RJ, and others (2004) Large-scale geographical variation confirms that climate change causes birds to lay earlier. Proc R Soc Lond B 271: $1657-1662$

Both C, Bouwhuis S, Lessells CM, Visser ME (2006) Climate change and population declines in a long-distance migratory bird. Nature 441:81-83

Burnham KP, Anderson DR (2002) Model selection and multimodel inference. Springer, New York

Catchpole CK, Slater PJB 1995. Bird song: biological themes and variations. Cambridge University Press, Cambridge

Cramp S (1998) The complete birds of the western Palearctic. Oxford University Press, Oxford (CD-ROM)

- Crick HQP, Sparks TH (1999) Climate change related to egglaying trends. Nature 399:423

Curio E (1959) Verhaltensstudien am Trauerschnäpper; Beiträge zur Ethologie und Ökologie von Muscicapa $h$. hypoleuca Pallas. Parey, Berlin

Drovetski SV, Zink RM, Fadeev IV, Nesterov EV, Koblik EA, Red'kin YA, Rohwer S (2004) Mitochondrial phylogeny of Locustella and related genera. J Avian Biol 35:105-110

Dunn PO (2004) Breeding dates and reproductive performance. Adv Ecol Res 35:67-85

$>$ Dunn PO, Winkler DW (1999) Climate change has affected the breeding date of tree swallows throughout North America. Proc R Soc Lond B 266:2487-2490

Dunning JB (1993) Handbook of avian body masses. CRC Press, Boca Raton, FL

> Felsenstein J (1985) Phylogenies and the comparative method. Am Nat 125:1-15

- Fontaine JJ, Decker KL, Skagen SK, van Riper C III (2009) Spatial and temporal variation in climate change: a bird's eye view. Clim Change 97:305-311

$>$ Garson PJ, Hunter ML Jr (1979) Effects of temperature and time of year on the singing behaviour of wrens Troglodytes troglodytes and great tits Parus major. Ibis 121:481-487

- Gienapp P, Leimu R, Merilä J (2007) Responses to climate change in avian migration time-microevolution versus phenotypic plasticity. Clim Res 35:25-35

Gienapp P, Teplitsky C, Alho JS, Mills JA, Merilä J (2008) Climate change and evolution: disentangling environmental and genetic responses. Mol Ecol 17:167-178

- Gill FB, Slikas B, Sheldon FH (2005) Phylogeny of titmice (Paridae): II. Species relationships based on sequences of the mitochondrial cytochrome- $b$ gene. Auk 122:121-143

Hurrell JW (1995) Decadal trends in the North-Atlantic Oscillation: regional temperatures and precipitation. Science 269:676-679

IPCC (2001) Climate change 2001: the scientific basis. Contribution of Working Group I to the Third Assessment Report of the Intergovernmental Panel on Climate Change. Cambridge University Press, Cambridge

IPCC (2007) Climate change 2007: the physical science basis. Contribution of Working Group I to the Fourth Assessment Report of the Intergovernmental Panel on Climate Change. Cambridge University Press, Cambridge

Jenkins D, Watson A (2000) Dates of first arrival and song of birds during 1974-99 in mid-Deeside, Scotland. Bird Study 47:249-251

Johnson KP, de Kort S, Dinwoodey K, Mateman AC, ten Cate C, Lessells CM, Clayton DH (2001) A molecular phylogeny of the dove genera Streptopelia and Columba. Auk 118:874-887

> Jones T, Cresswell W (2010) The phenology mismatch hypothesis: Are declines of migrant birds linked to uneven global climate change? J Anim Ecol 79:98-108

> Jonzén N, Lindén A, Ergon T, Knudsen E, and others (2006) Rapid advance of spring arrival dates in long-distance migratory birds. Science 312:1959-1961 
Lack D (1954) The natural regulation of animal numbers. Methuen, London

Lehikoinen E, Sparks TH, Zalakevicius M (2004) Arrival and departure dates. Adv Ecol Res 35:1-31

Leisler B, Heidrich P, Schulze-Hagen K, Wink W (1997) Taxonomy and phylogeny of reed warblers (genus Acrocephalus) based on mtDNA sequences and morphology. J Ornithol 138:469-496

McClave JT, Sincich T (2003) Statistics, 9th edn. Prentice Hall, Englewood Cliffs, NJ

Møller AP (2007) Tardy females, impatient males: protandry and divergent selection on arrival date in the two sexes of the barn swallow. Behav Ecol Sociobiol 61:1311-1319

Møller AP, Brohede J, Cuervo JJ, de Lope F, Primmer CR (2003) Extrapair paternity in relation to sexual ornamentation, arrival date and condition in a migratory bird. Behav Ecol 14:707-712

Møller AP, Fiedler W, Berthold P (eds) (2004) Birds and climate change. Elsevier, Amsterdam

Møller AP, Rubolini D, Lehikoinen E (2008) Populations of migratory bird species that did not show a phenological response to climate change are declining. Proc Natl Acad Sci USA 105:16195-16200

Møller AP, Flensted-Jensen E, Klarborg K, Mardal W, Nielsen JT (2010) Climate change affects the duration of the reproductive season in birds. J Anim Ecol (in press). doi:10. 1111/j.365-2565.2010.01677.x

Przybylo R, Sheldon BC, Merilä J (2000) Climate effects on breeding and morphology: evidence for phenotypic plasticity. J Anim Ecol 69:395-403

Pulido F, Berthold P (2004) Microevolutionary response to climatic change. Adv Ecol Res 35:151-184

Pulido F, Widmer M (2005) Are long-distance migrants constrained in their evolutionary response to environmental change? Causes of variation in the timing of autumn migration in a blackcap ( $S$. atricapilla) and two garden warbler (Sylvia borin) populations. Ann NY Acad Sci 1046: 228-241

Purvis A, Rambaut A (1995) Comparative analysis by independent contrasts (CAIC). Comput Appl Biosci 11:247-251

R Development Core Team (2008) R: a language and environment for statistical computing, reference index version 2.8.1. R Foundation for Statistical Computing, Vienna, available at www.r-project.org

Root TL, Price JL, Hall KR, Schneider SH and others (2003) Fingerprints of global warming on wild animals and plants. Nature 421:57-60

Rubolini D, Spina F, Saino N (2005) Correlates of timing of spring migration in birds: a comparative study of transSaharan migrants. Biol J Linn Soc 85:199-210

Rubolini D, Møller AP, Rainio K, Lehikoinen E (2007) Intraspecific consistency and geographic variability in temporal trends of spring migration phenology among European bird species. Clim Res 35:135-146

Editorial responsibility: Tim Sparks, Cambridge, UK
Saino N, Szép T, Romano M, Rubolini D, Spina F, Møller AP (2004) Ecological conditions during winter predict arrival date at the breeding quarters in a trans-Saharan migratory bird. Ecol Lett 7:21-25

Saino N, Rubolini D, Jonzén N, Ergon T, Montemaggiori A, Stenseth NC, Spina F (2007) Temperature and rainfall anomalies in Africa predict timing of spring migration in trans-Saharan migratory birds. Clim Res 35:123-134

Sanderson FJ, Donald PF, Pain DJ, Burfield IJ, van Bommel FPJ (2006) Long-term population declines in Afro-Palearctic migrant birds. Biol Conserv 131:93-105

Sanz JJ, Potti J, Moreno J, Merino S, Frias O (2003) Climate change and fitness components of a migratory bird breeding in the Mediterranean region. Glob Change Biol 9: 461-472

Schmidt E, Hüppop K (2007) Erstbeobachtung und Sangesbeginn von 97 Vogelarten in den Jahren 1963 bis 2006 in einer Gemeinde im Landkreis Parchim (MecklenburgVorpommern). Vogelwarte 45:27-58

Sheldon BC, Kruuk LEB, Merilä J (2003) Natural selection and inheritance of breeding time and clutch size in the collared flycatcher. Evolution 57:406-420

Sibley CG, Ahlquist JE (1990) Phylogeny and classification of birds. Yale University Press, New Haven, CT

Spottiswoode CM, Møller AP (2004) Extrapair paternity, migration, and breeding synchrony in birds. Behav Ecol 15:41-57

Strain JG, Mumme RL (1988) Effects of food supplementation, song playback, and temperature on vocal territorial behavior of Carolina wrens. Auk 105:11-16

Tøttrup AP, Thorup K, Rainio K, Yosef R, Lehikoinen E, Rahbek C (2008) Avian migrants adjust migration in response to environmental conditions en route. Biol Lett 4:685-688

Tryjanowski P, Kuzniak S, Sparks T (2005) What affects the magnitude of change in first arrival dates of migrant birds? J Ornithol 146:200-205

Végvári Z, Bokony V, Barta Z, Kovacs G (2010) Life history predicts advancement of avian spring migration in response to climate change. Glob Change Biol 16:1-11

Visser ME (2008) Keeping up with a warming world; assessing the rate of adaptation to climate change. Proc $\mathrm{R}$ Soc Lond B 275:649-659

- Visser ME, Perdeck AC, van Balen JH, Both C (2009) Climate change leads to decreasing bird migration distances. Glob Change Biol 15:1859-1865

Walther GR, Post E, Convey P, Menzel A, and others (2002) Ecological responses to recent climate change. Nature 416:389-395

Werner A, Schönwiese CD (2002) A statistical analysis of the North Atlantic oscillation and its impact on European temperature. Glob Atmos Ocean Syst 8:293-306

Zuur AF, Ieno EI, Walker NJ, Saveliev AA, Smith GM (2009) Mixed effects models and extensions in ecology with $\mathrm{R}$. Springer, New York

Submitted: January 4, 2010; Accepted: April 3, 2010

Proofs received from author(s): May 20, 2010 